\title{
The optic disc in glaucoma. IV: Optic disc evaluation in the ocular hypertensive patient
}

\author{
R. A. HITCHINGS AND C. A. WHEELER \\ From the Department of Ophthalmology, King's College Hospital, \\ Denmark Hill, London SE5 $9 R S$
}

SUMMARY A prospective study was carried out over a 3-year period on patients with one normotensive eye and one eye with ocular hypertension. A greater variability in the responses to visual field testing was apparent in the hypertensive eye, but only on comparison of serial visual fields. Analysis of the stereo disc photographs demonstrated larger cup to disc ratios in the hypertensive eye without changes in the nerve fibre layer to equate with the visual field response. Stereo disc photography is a quick and simple method of recording changes in the optic disc and should be considered in the follow-up of ocular hypertensive patients.

The incidence of ocular hypertension (an intraocular pressure $>21 \mathrm{mmHg}$ without visual field defects and glaucomatous cupping) far exceeds the incidence of glaucoma. Actuarial analysis ${ }^{1}$ and longterm follow up studies of ocular hypertensives ${ }^{23}$ suggest that a large proportion of eyes with an intraocular pressure $>21 \mathrm{mmHg}$ without other signs of glaucoma will not progress to develop the disease $(>50 \%$ in 15 years according to Sorensen et $a l^{3}$ ). The decision on which patient with ocular hypertension alone requires treatment must therefore be based on factors other than recognition of elevated intraocular pressure. These factors may be grouped. Firstly, the existence of so-called high risk factors, found in a larger proportion of glaucoma patients than normals, such as a $\mathrm{Po} / \mathrm{C}>100$ after water drinking, ${ }^{4}$ high myopia, ${ }^{5}$ diabetes, ${ }^{6}$ and a positive family history. ${ }^{7}$ However, these high-risk factors do occur in the normal population, and, in view of the relatively low prevalence of glaucoma, the chances are that for any individual discovered to have a high-risk factor he will not have glaucoma.

Secondly, predictive factors have been investigated to see whether any one is especially linked to the future development of glaucoma. If the initial intraocular pressure exceeds $30 \mathrm{mmHg}$, then the chances of eventual field defects developing are quite high (7 out of 17 in 5 years, ${ }^{8} 2$ out of 8 in 9 years, ${ }^{9}$ and 5 out of 17 in 5 years ${ }^{10}$ ). However, many eyes have been shown in prospective studies to develop field defects despite an initial intraocular

Correspondence to Mr Roger A. Hitchings. pressure of below $30 \mathrm{mmHg}$. Other predictive factors that have failed to stand the test of a prospective study have included $\mathrm{Po} / \mathrm{C} 100^{911}$ and an initial C/D ratio $>0 \cdot 5 .{ }^{9} 12$

Lastly, several biochemical and other markers for chronic simple glaucoma have been suggested. All have had doubts cast upon their usefulness. For example, steroid responsiveness, ${ }^{913}$ HLA typing, ${ }^{14}$ and the response to topical epinephrine. ${ }^{15}$

In the absence of any test or group of tests that would allow identification of the future glaucoma patient from a group of ocular hypertensives the clinician needs to resort to long-term follow-up. Several authors have commented on changes in visual function or fundal appearance in the ocular hypertensive. Fishman ${ }^{16}$ noted, and Portnoy ${ }^{17}$ measured, optic disc (cup) asymmetry in ocular hypertensives while Sommer et al..$^{18}$ demonstrated defects in the retinal nerve fibre bundle layer in the eyes of patients who subsequently developed glaucomatous visual field defects. Werner and Drance ${ }^{19}$ detected 'localised minor disturbances' on visual field testing at the site of a later developing visual field defect. Lakowski et al.$^{20}$ found higher 100 hue scores in ocular hypertensive patients than normal persons.

Each of the above signs was assessed separately in different studies. To try and assess the relative incidence of these signs in ocular hypertensives the authors selected a group of patients with uniocular hypertension. These patients were entered into a prospective study and followed over a 3-year period. During that time tests of visual function and observations of fundal appearances were made. 


\section{Patients and methods}

Patients were entered into the study if, over a 6month period, the intraocular pressure in one eye was consistently above $21 \mathrm{mmHg}$ and in the other eye consistently below $21 \mathrm{mmHg}$, together with a normal 3 isopter Goldmann field ${ }^{21}$ and if the eyes were without evidence for other ocular disease. Ten patients fulfilled these criteria.

Patients were seen every 6 months for an initial 12-month period. At each visit the following tests were performed: intraocular pressure check by applanation tonometry, visual fields testing by Friedmann analyser, mydriasis and slit-lamp fundoscopy followed by stereodisc photography using colour film with a $\times 2$ adaptor. The stereoscopic effect was obtained by standard movement of the optic disc within the grid of the objective lens. ${ }^{22}$ Care was taken to focus on the nerve fibre layer.

At the end of the 12-month follow-up period visual field testing was supplemented by static field testing on the Tubingen Oculus Perimeter. The patients attended on 2 separate days for the visual field test. At the time of the first visit an initial measurement was made of the intraocular pressure and the pupils were dilated with cyclopentolate $1 \%$ and phenylephrine $10 \%$; central visual field analysis was performed. The photopic static cuts were performed in a standard manner, ${ }^{23}$ a single radial 'cut' being made in each quadrant. Finally a peripheral field was obtained and the intraocular pressures measured. At the time of the second visit the pupils were again dilated and the patient dark-adapted for 30 minutes. An analysis of the scotopic field was made. On this occasion the patient fixed on a red $10^{\circ}$ fixation target of minimum illumination that could be comfortably seen. The test target was 104 seconds in diameter presented for $1 / 10$ th of a second. The threshold of every 4th degree from $1^{\circ}$ through $25^{\circ}$ was assessed, followed by the threshold of every 4th degree from $23^{\circ}$ to $3^{\circ}$. The macular sensitivity was checked 3 times with a $42^{\circ}$ target. Finally a Friedmann field analysis was performed, the threshold for each patient being found.

These static perimetric examinations were performed every six months for an 18-24-month period, a minimum of 2 (1 patient) and a maximum of 4 (1 patient) such tests were performed.

The optic disc photographs were collected at the end of the 3-year period and examined by the writers in 3 ways, on each occasion without the name of the patient or the hypertensive eye being known. Firstly, the disc photographs were presented in sequence for each eye and examined for changes in the visibility of the nerve fibre layer, the dimensions of the cup orifice, and the shape of the optic cup. ${ }^{22}$
Secondly, the photographs were presented as stereo pairs of the 2 eyes of each patient to compare the $C / D$ ratio, the cup volume, and the visibility of the nerve fibre layer of the 2 eyes. Thirdly, black-andwhite prints were made from the photographs taken of each patient at the time of the last visit. After the configuration of the cup orifice had been checked with the corresponding stereo disc photographs a pencil line was drawn round the margin of the optic cup and the optic disc allowing a numerical value for the $C / D$ ratio to be obtained. ${ }^{24}$ This numerical value for the $C / D$ ratio was compared for the 2 eyes of each patient. Finally, the photographs were identified, with the name of the patient and the hypertensive eye being noted.

\section{Results}

Of the 10 patients entered 1 died after 18 months and is not reported on here. The results are summarised in the tables. Table 1 shows the intraocular pressures during the period of study. The mean

Table 1 Intraocular pressure measurement

\begin{tabular}{|c|c|c|c|c|c|c|c|c|}
\hline \multirow{3}{*}{$\begin{array}{l}\text { Patient } \\
\text { no. }\end{array}$} & \multirow{3}{*}{\multicolumn{2}{|c|}{$\begin{array}{l}\text { Mean IOP } \\
\text { in first } \\
12 \text { months }\end{array}$}} & \multicolumn{6}{|c|}{ Mean IOP in last $18-24$ months } \\
\hline & & & \multicolumn{3}{|c|}{ Premydriasis } & \multicolumn{3}{|c|}{ Postmydriasis } \\
\hline & & & $I O P$ & $S E M$ & $\begin{array}{l}\text { No. } \\
\text { obser- } \\
\text { vations }\end{array}$ & $I O P$ & $S E M$ & $\begin{array}{l}\text { No. } \\
\text { obser- } \\
\text { vations }\end{array}$ \\
\hline \multirow[t]{2}{*}{1} & $\mathbf{R}$ & 27 & $28 \cdot 3$ & $\pm 1 \cdot 16$ & 8 & $24 \cdot 9$ & $\pm 1 \cdot 02$ & 8 \\
\hline & $\mathbf{L}$ & $22 \cdot 5$ & $23 \cdot 1$ & \pm 0.41 & & $22 \cdot 5$ & \pm 0.67 & \\
\hline \multirow[t]{2}{*}{2} & $\mathbf{R}$ & 28 & $19 \cdot 6$ & $\pm 1 \cdot 8$ & 9 & $24 \cdot 6$ & $\pm 0 \cdot 26$ & 9 \\
\hline & $\mathbf{L}$ & 17 & $15 \cdot 2$ & \pm 1.06 & & $20 \cdot 0$ & \pm 0.53 & \\
\hline \multirow[t]{2}{*}{$3^{1}$} & $\mathbf{R}$ & 32 & $26 \cdot 3$ & $\pm 1 \cdot 5$ & 9 & $31 \cdot 0$ & \pm 0.83 & 9 \\
\hline & $\mathbf{L}$ & $21 \cdot 3$ & $18 \cdot 8$ & $\pm 0 \cdot 58$ & & $22 \cdot 1$ & \pm 0.57 & \\
\hline \multirow[t]{2}{*}{4} & $\mathbf{R}$ & $16 \cdot 3$ & $17 \cdot 8$ & \pm 0.7 & 4 & $20 \cdot 3$ & $\pm \mathbf{2 \cdot 1}$ & 4 \\
\hline & $\mathbf{L}$ & 25 & $19 \cdot 8$ & $\pm 1 \cdot 75$ & & $22 \cdot 3$ & \pm 1.75 & \\
\hline \multirow[t]{2}{*}{5} & $\mathbf{R}$ & $28 \cdot 5$ & $22 \cdot 6$ & \pm 1.04 & 10 & 34.0 & \pm 2.34 & 10 \\
\hline & $\mathbf{L}$ & 19.5 & 17.5 & \pm 0.72 & & $20 \cdot 2$ & $\pm 1 \cdot 33$ & \\
\hline \multirow[t]{2}{*}{$6^{2}$} & $\mathbf{R}$ & $30 \cdot 7$ & 29.9 & \pm 3.50 & 7 & 38.9 & \pm 1.93 & 7 \\
\hline & $\mathbf{L}$ & $18 \cdot 3$ & $21 \cdot 3$ & $\pm 0 \cdot 30$ & & $22 \cdot 3$ & \pm 0.60 & \\
\hline \multirow[t]{2}{*}{$7^{3}$} & $\mathbf{R}$ & 50.0 & 20.9 & \pm 0.38 & 9 & $22 \cdot 8$ & \pm 0.63 & 9 \\
\hline & $\mathbf{L}$ & 19 & $19 \cdot 4$ & \pm 0.72 & & $25 \cdot 5$ & $\pm 3 \cdot 33$ & \\
\hline \multirow[t]{2}{*}{8} & $\mathbf{R}$ & $18 \cdot 7$ & $19 \cdot 5$ & \pm 0.42 & 9 & $28 \cdot 3$ & $\pm 4 \cdot 6$ & 9 \\
\hline & $\mathbf{L}$ & $30 \cdot 7$ & $28 \cdot 8$ & $\pm 4 \cdot 6$ & & $36 \cdot 7$ & $\pm 2 \cdot 33$ & \\
\hline \multirow[t]{2}{*}{$9^{14}$} & $\mathbf{R}$ & 53.5 & $24 \cdot 9$ & \pm 1.56 & 9 & $45 \cdot 1$ & \pm 3.67 & 9 \\
\hline & $\mathbf{L}$ & 22.5 & 16.9 & \pm 0.76 & & $20 \cdot 0$ & \pm 0.73 & \\
\hline
\end{tabular}

'Presenting IOP $<21 \mathrm{mmHg}$, subsequent IOP $>21 \mathrm{mmHg}$. ${ }^{2}$ Progressive IOP rise required antiglaucoma treatment in the last 18 months. ${ }^{3}$ Presenting IOP $50 \mathrm{mmHg}$, subsequent $R$ filter operation. ${ }^{4}$ Progressive IOP rise required antiglaucoma treatment to $R$ eye throughout. 
Table 2 Results of visual field testing

\begin{tabular}{|c|c|c|c|c|c|c|c|}
\hline \multirow{2}{*}{$\begin{array}{l}\text { Patient } \\
\text { no. }\end{array}$} & \multirow{2}{*}{$\begin{array}{l}\text { No. of } \\
\text { times tests } \\
\text { performed }\end{array}$} & \multirow{2}{*}{$\begin{array}{l}\text { Hypertensive } \\
\text { eye }\end{array}$} & \multirow{2}{*}{$\begin{array}{l}\text { Tested } \\
\text { eye }\end{array}$} & \multicolumn{4}{|c|}{ Sensitivity reduction in one or more quadrants } \\
\hline & & & & Photopic cuts & Scotopic field & Friedmann & $\begin{array}{l}\text { Peripheral } \\
\text { isopter }\end{array}$ \\
\hline \multirow[t]{2}{*}{1} & 3 & $\mathbf{R}$ & $\mathbf{R}$ & $\begin{array}{l}\text { UT sens. decr. } \frac{2}{3} \\
\text { LT sens. decr. } \frac{2}{3}\end{array}$ & LT sens. decr. $\frac{1}{3}$ & UT sens. decr. $\frac{?}{3}$ & NAD \\
\hline & & & $\mathbf{L}$ & UT sens. decr. $\frac{1}{3}$ & NAD & NAD & NAD \\
\hline \multirow[t]{2}{*}{2} & 3 & $\mathbf{R}$ & $\mathbf{R}$ & $\begin{array}{l}\text { UT sens. decr. } \frac{1}{3} \\
\text { UN sens. decr. } \frac{1}{3}\end{array}$ & NAD & Sens. decr. $\frac{2}{3}$ & NAD \\
\hline & & & L & NAD & NAD & Sens. decr. $\frac{1}{3}$ & NAD \\
\hline \multirow[t]{2}{*}{3} & 3 & $\mathbf{R}$ & $\mathbf{R}$ & $\begin{array}{l}\text { UR sens. decr. } \frac{2}{3} \\
\text { LT sens. decr. } \frac{2}{3}\end{array}$ & $\begin{array}{l}\text { Sens. decr. } \frac{1}{3} \\
\text { Sens. incr. } \frac{1}{3}\end{array}$ & UT sens. decr. $\frac{2}{3}$ & NAD \\
\hline & & & $\mathbf{L}$ & NAD & NAD & NAD & NAD \\
\hline \multirow[t]{2}{*}{4} & 2 & $\mathbf{L}$ & $\mathbf{R}$ & $\begin{array}{l}\text { UT sens. decr. } \frac{1}{2} \\
\text { LT sens. decr. } \frac{1}{2} \\
\text { LN sens. decr. } \frac{1}{2} \\
\text { LT sens. decr. } \frac{1}{2}\end{array}$ & NAD & $\begin{array}{l}\text { UN sens. decr. } \frac{1}{2} \\
\text { LT sens. decr. } \frac{1}{2}\end{array}$ & NAD \\
\hline & & & $\mathbf{L}$ & NAD & NAD & NAD & NAD \\
\hline \multirow[t]{2}{*}{5} & 4 & $\mathbf{R}$ & $\mathbf{R}$ & $\begin{array}{l}\text { UT sens. decr. } \frac{1}{4} \\
\text { LT sens. decr. }\end{array}$ & $\begin{array}{l}\text { UN sens. incr. } 1 \\
\text { LT sens. decr. }\end{array}$ & $\begin{array}{l}\text { LT sens. decr. } \frac{1}{4} \\
\text { UT sens. decr. } \frac{1}{4}\end{array}$ & NAD \\
\hline & & & $\mathbf{L}$ & NAD & Sens. incr. $\frac{1}{4}$ & $\begin{array}{l}\text { LT sens. decr. } \\
\text { LN sens. decr. }\end{array}$ & NAD \\
\hline \multirow[t]{2}{*}{6} & 3 & $\mathbf{R}$ & $\mathbf{R}$ & $\begin{array}{l}\text { UT sens. decr. } \frac{2}{3} \\
\text { UN sens. decr. } \frac{2}{3} \\
\text { LT sens. decr. } \frac{1}{3}\end{array}$ & $\begin{array}{l}\text { UT sens. decr. } \frac{2}{3} \\
\text { LN sens. decr. } \frac{1}{3}\end{array}$ & $\begin{array}{l}\text { UT sens. decr. } \frac{1}{3} \\
\text { UT sens. decr. } \frac{1}{3}\end{array}$ & Variable $\frac{1}{3}$ \\
\hline & & & $\mathbf{L}$ & $\begin{array}{l}\text { UT sens. decr. } \frac{1}{3} \\
\text { LT sens. decr. } \frac{1}{3}\end{array}$ & LN sens. decr. $\frac{1}{3}$ & UT sens. decr. $\frac{1}{3}$ & \\
\hline \multirow[t]{2}{*}{7} & 3 & $\mathbf{R}$ & $\mathbf{R}$ & $\begin{array}{l}\text { UT sens. decr. } 3 / 3 \\
\text { UN sens. decr. } 3 / 3 \\
\text { LT sens. decr. } 3 / 3 \\
\text { LN sens. decr. } 3 / 3\end{array}$ & $\begin{array}{l}\text { UT sens. decr. } 3 / 3 \\
\text { UN sens. decr. } 3 / 3 \\
\text { LT sens. decr. } 3 / 3 \\
\text { LN sens. decr. } 3 / 3\end{array}$ & UN sens. decr. $3 / 3$ & $\begin{array}{l}\text { UN field } \\
\text { defect } 3 / 3\end{array}$ \\
\hline & & & $\mathbf{L}$ & UT sens. decr. $\frac{1}{s}$ & NAD & NAD & NAD \\
\hline \multirow[t]{2}{*}{8} & 3 & $\mathbf{L}$ & $\mathbf{R}$ & NAD & NAD & NAD & NAD \\
\hline & & & $\mathbf{L}$ & $\begin{array}{l}\text { UN sens. decr. } \frac{1}{3} \\
\text { UT sens. decr. } \frac{1}{b} \\
\text { LT sens. decr. } 2 / 3 \\
\text { Cen. sens. decr. } 2 / 3\end{array}$ & Sens. decr. $3 / 3$ & UT sens. decr. $2 / 3$ & NAD \\
\hline \multirow[t]{2}{*}{9} & 3 & $\mathbf{R}$ & $\mathbf{R}$ & $\begin{array}{l}\text { UN sens. decr. } 2 / 3 \\
\text { UT sens. decr. } 2 / 3 \\
\text { LN sens. decr. } 2 / 3 \\
\text { LT sens. decr. } 2 / 3 \\
\text { Cen. sens. decr. } 1 / 3\end{array}$ & $\begin{array}{l}\text { UT sens. decr. } 1 / 3 \\
\text { LT sens. decr. } 1 / 3\end{array}$ & $\begin{array}{l}\text { UN sens. decr. } 1 / 3 \\
\text { UT sens. decr. } 1 / 3\end{array}$ & Constricted $1 / 3$ \\
\hline & & & $\mathbf{L}$ & LT sens. incr. $1 / 3$ & UT sens. decr. $1 / 3$ & $\begin{array}{l}\text { UT sens. decr. } 2 / 3 \\
\text { UN sens. decr. } 2 / 3\end{array}$ & NAD \\
\hline
\end{tabular}

$\mathrm{UT}=$ upper temporal. $\mathrm{UN}=$ upper nasal. Sens.=sensitivity. Decr. =decreased. Incr. =increased. $\mathbf{L T}=$ lower temporal. $\mathrm{LN}=$ lower nasal. Cen. $=$ central. Numerator $=$ no. times reduced sensitivity. Denominator $=$ no. times tested. 


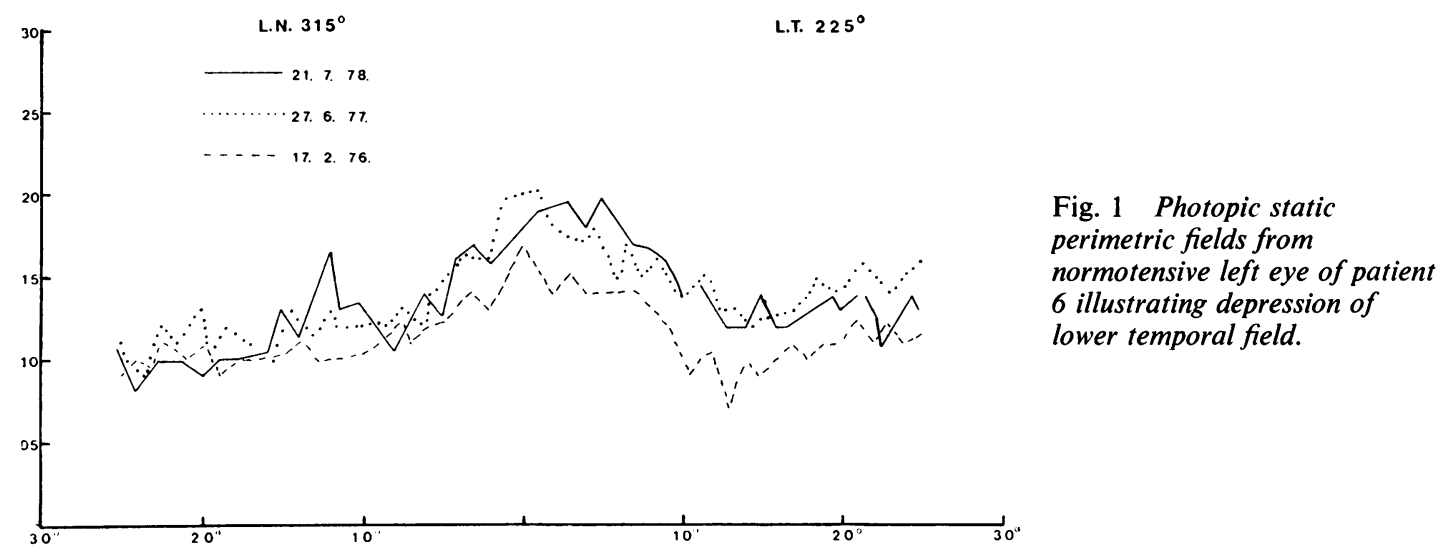

intraocular pressures are given for the first 12 months. Patient no. 7 developed a permanent visual field defect and eventually required filtration surgery. The visual field and optic disc results for this patient are presented as they form a useful comparison with the other, ocular hypertensive, patients. Three patients (nos. 1, 3, and 9) ran occasional pressures greater than $21 \mathrm{mmHg}$ in the 'normotensive' eye over the first 12 months, but there was always a minimum of $5 \mathrm{mmHg}$ difference between the 2 eyes. Two patients (nos. 6 and 9) required antiglaucoma treatment to lower the intraocular pressure from $>40 \mathrm{mmHg}$ to $<30 \mathrm{mmHg}$ during the trial.

The results of visual fields testing are seen in Table 2. The hypertensive eye for each patient can be seen on sequential field testing to have a far greater variability in response. Reduced sensitivity was considered present either if there was a localised depression greater than $0.5 \mathrm{log}$ unit $^{19}$ in one part of the visual field on photopic testing (Fig. 1) or generalised depression of the whole of one or more radial cuts when compared with the corresponding quadrant of the opposite eye seen on scotopic testing (Fig. 2). Reduced sensitivity was not found to be associated with isolated episodes of marked ocular hypertension. With the exception of patient 7 , who had frank glaucoma in one eye, no patient had a permanent alteration in visual field sensitivity during the period of study.

Most eyes showed an increase in intraocular pressure following mydriasis. In no case was this caused by angle closure.

The results of optic disc analysis are seen on Tables 3 and 4. Analysis of sequential disc photographs failed to show progressive change in any case. Comparison of stereo photographs of the 2 eyes for each patient showed the optic cup orifice and volume to be larger in the hypertensive eye (Table 3, Figs. 3 and 4). Quantitative measurement of the cup/disc ratio showed the hypertensive eye to have the larger C/D ratio in all bar 2 patients (nos. 2 and 4, whose intraocular pressures reverted to normal). The C/D difference between the 2 eyes

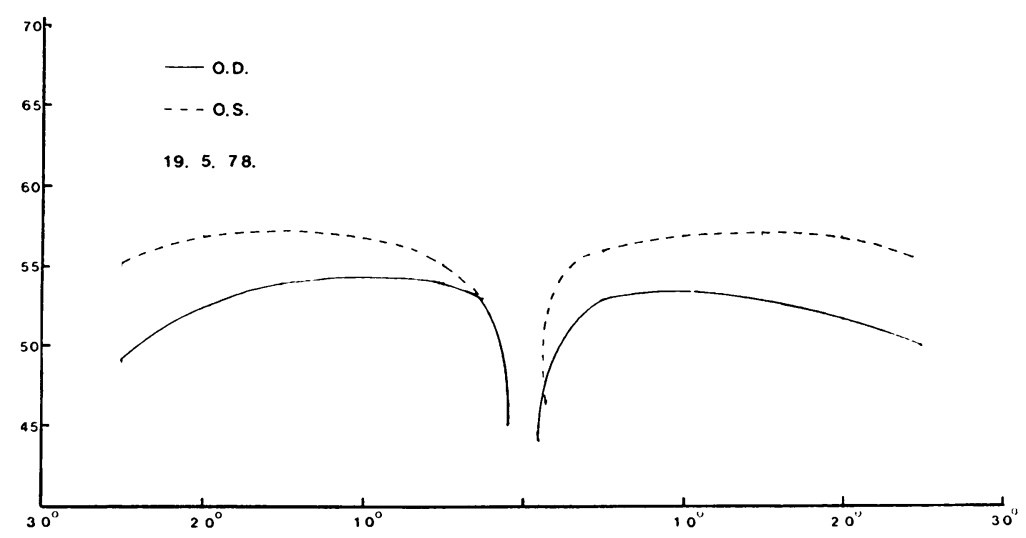

Fig. 2 Scotopic static perimetric fields showing generalised depression of the visual field in the hypertensive right eye of patient 3 . Note: Oculus perimetric fields are shown: vertical axis represents logarithmic changes in target luminosity. Horizontal axis represents degrees either side of fixation. 
ranged from 0.07 to 0.53 , while the percentage increase in C/D ratio of the hypertensive eye compared with the normotensive eye ranged from $16 \%$ to $170 \%$. The results of 100 hue testing are seen on Table 4. The patients in this study failed to give consistently higher 100 hue scores in the hypertensive eye.

Table 3 Results of subjective optic disc analysis

\begin{tabular}{lllll}
\hline $\begin{array}{l}\text { Patient } \\
\text { no. }\end{array}$ & $\begin{array}{l}\text { Hypertensive } \\
\text { eye }\end{array}$ & $\begin{array}{l}\text { C/D } \\
\text { ratio }\end{array}$ & $\begin{array}{l}\text { Cup } \\
\text { volume }\end{array}$ & $\begin{array}{l}\text { Visibility nerve } \\
\text { fibre layer }\end{array}$ \\
\hline $\mathbf{1}$ & $\mathbf{R}$ & $\mathbf{R}>\mathbf{L}$ & $\mathbf{R}>\mathbf{L}$ & Visible R \& $\mathbf{~}$ \\
$\mathbf{2}$ & $\mathbf{R}$ & $\mathbf{R}>\mathbf{L}$ & $\mathbf{R}>\mathbf{L}$ & Visible R \& L \\
$\mathbf{3}$ & $\mathbf{R}$ & $\mathbf{R}>\mathbf{L}$ & $\mathbf{R}>\mathbf{L}$ & Visible R \& L \\
$\mathbf{4}$ & $\mathbf{L}$ & $\mathbf{R}=\mathbf{L}$ & $\mathbf{R}=\mathbf{L}$ & Visible R \& L \\
$\mathbf{5}$ & $\mathbf{R}$ & $\mathbf{R}>\mathbf{L}$ & $\mathbf{R}>\mathbf{L}$ & Visible R \& L \\
$\mathbf{6}$ & $\mathbf{R}$ & $\mathbf{R}>\mathbf{L}$ & $\mathbf{R}>\mathbf{L}$ & Visible R \& L \\
$\mathbf{7}$ & $\mathbf{R}$ & $\mathbf{R}>\mathbf{L}$ & $\mathbf{R}>\mathbf{L}$ & $\begin{array}{l}\text { Invisible } \mathbf{R} \\
\text { Visible } \mathbf{L}\end{array}$ \\
$\mathbf{8}$ & & $\mathbf{R}=\mathbf{L}$ & $\mathbf{R}=\mathbf{L}$ & Invisible R \& L \\
$\mathbf{9}$ & $\mathbf{L}$ & $\mathbf{R}>\mathbf{L}$ & $\mathbf{R}>\mathbf{L}$ & Invisible R \& L \\
\hline
\end{tabular}

Table 4 Vertical $C / D$ ratio and hundred hue response versus intraocular pressure

\begin{tabular}{|c|c|c|c|c|c|}
\hline $\begin{array}{l}\text { Patient } \\
\text { no. }\end{array}$ & Eye & $\begin{array}{l}\text { Mean IOP } \\
\text { over last } 18 \\
\text { months }\end{array}$ & $\begin{array}{l}\text { Vertical } \\
C / D \text { ratio }\end{array}$ & $\begin{array}{l}\text { Difference } \\
R \& L\end{array}$ & $\begin{array}{l}\text { Hundred } \\
\text { hue }\end{array}$ \\
\hline \multirow[t]{2}{*}{1} & $\mathbf{R}$ & 28.0 & 0.60 & $0 \cdot 16$ & 77 \\
\hline & $\mathbf{L}$ & $23 \cdot 1$ & 0.44 & & 42 \\
\hline \multirow[t]{2}{*}{2} & $\mathbf{R}$ & 19.6 & 0.43 & 0.02 & 11 \\
\hline & $\mathbf{L}$ & $15 \cdot 2$ & 0.41 & & 32 \\
\hline \multirow[t]{2}{*}{3} & $\mathbf{R}$ & $26 \cdot 3$ & 0.57 & 0.21 & 105 \\
\hline & $\mathbf{L}$ & 18.8 & 0.36 & & 116 \\
\hline \multirow[t]{2}{*}{4} & $\mathbf{R}$ & $17 \cdot 8$ & 0.21 & 0.06 & 44 \\
\hline & $\mathbf{L}$ & $19 \cdot 8$ & 0.27 & & 44 \\
\hline \multirow[t]{2}{*}{5} & $\mathbf{R}$ & $22 \cdot 6$ & 0.45 & $0 \cdot 16$ & 77 \\
\hline & $\mathbf{L}$ & $17 \cdot 5$ & $0 \cdot 29$ & & 81 \\
\hline \multirow[t]{2}{*}{6} & $\mathbf{R}$ & 29.9 & 0.72 & 0.21 & 129 \\
\hline & L & $21 \cdot 3$ & 0.51 & & 65 \\
\hline \multirow[t]{2}{*}{7} & $\mathbf{R}$ & 20.9 & 0.84 & 0.53 & - \\
\hline & $\mathbf{L}$ & $19 \cdot 4$ & $0 \cdot 31$ & & - \\
\hline \multirow[t]{2}{*}{8} & $\mathbf{R}$ & $19 \cdot 5$ & 0.43 & 0.07 & 374 \\
\hline & $\mathbf{L}$ & 28.8 & 0.50 & & 323 \\
\hline \multirow[t]{2}{*}{9} & $\mathbf{R}$ & 24.9 & 0.29 & $0 \cdot 12$ & 634 \\
\hline & $\mathbf{L}$ & 16.9 & $0 \cdot 17$ & & 374 \\
\hline
\end{tabular}

Fig. 3 Stereo photographs of hypertensive and normotensive eye of patient 6.
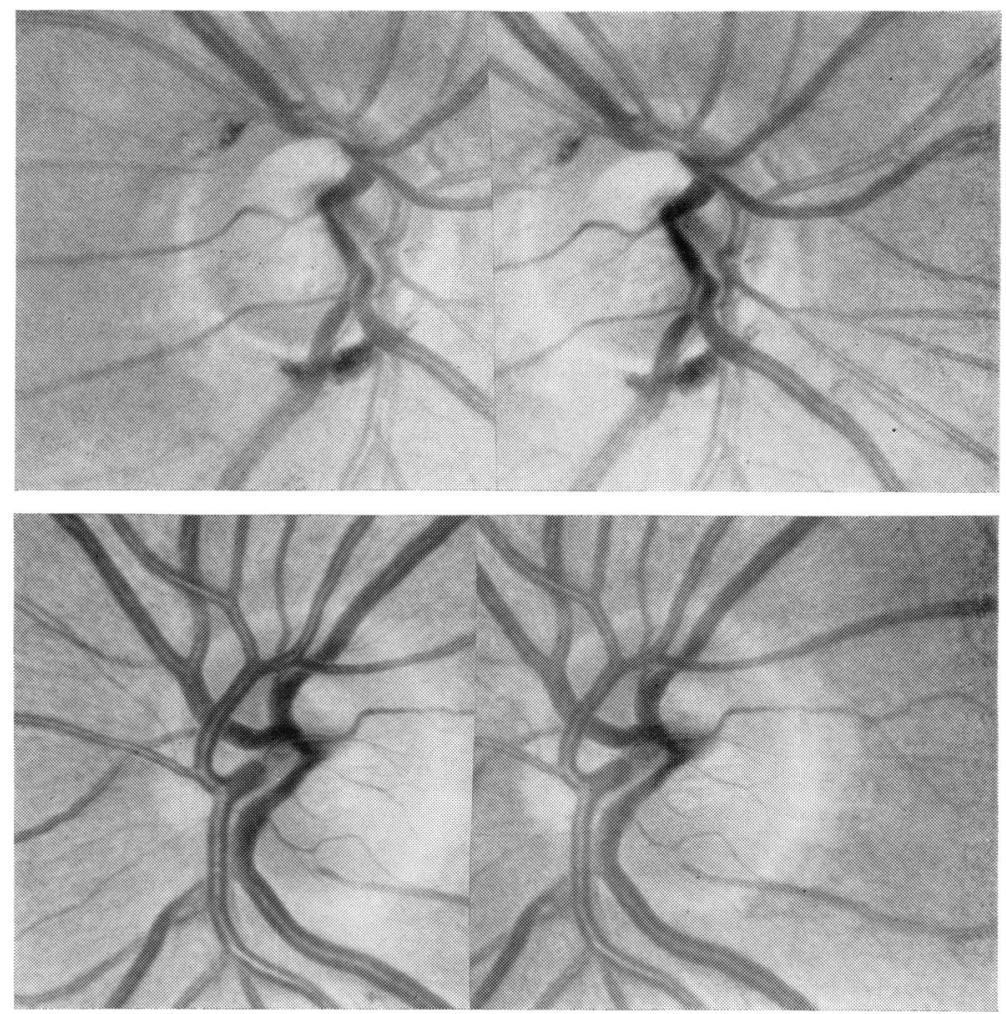

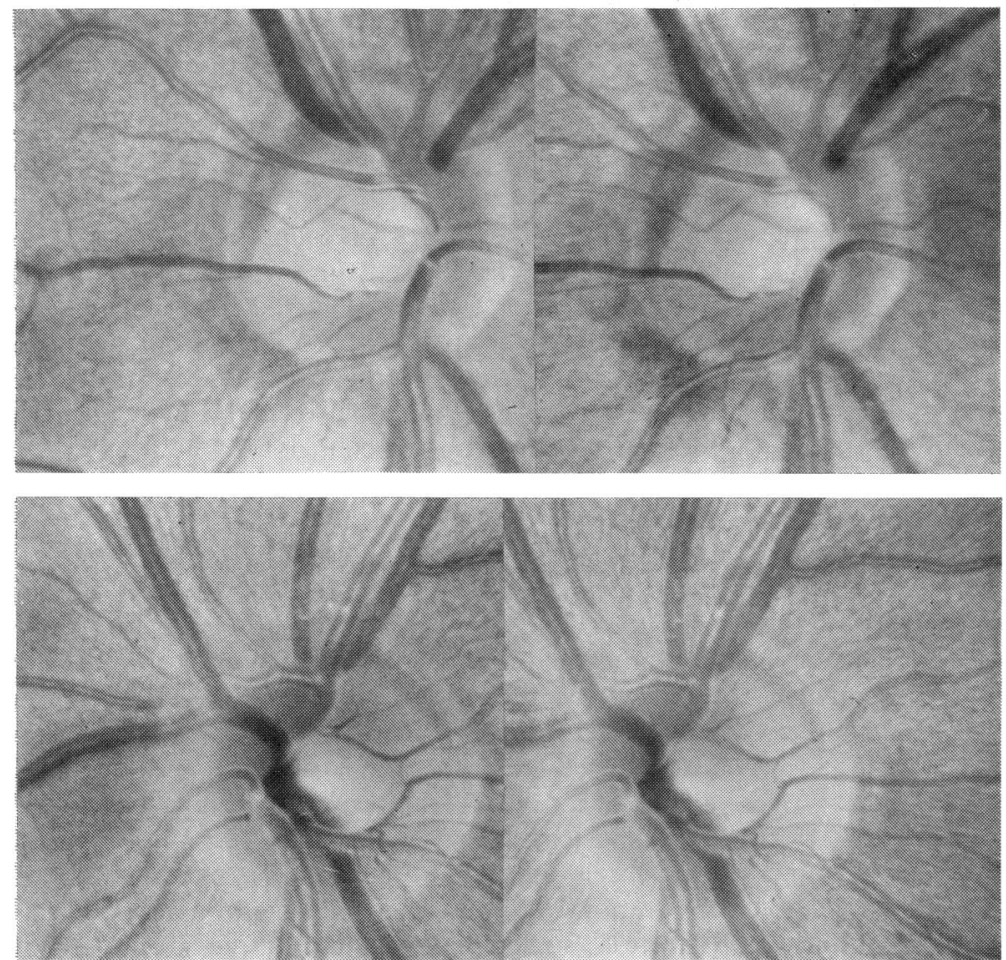

Fig. 4 Stereo photographs of hypertensive and normotensive eye of patient 2.

\section{Discussion}

The aim of any monitoring scheme for ocular hypertensive patients should be to use test methods that are accurate and reproducible. This study has compared a number of methods that could be so considered.

The patients tested in this study were entered on the basis of consistent ocular hypertension in one eye and consistently normal pressure in the second eye after they had been followed for a period of 6 months. As shown in Table 1, 2 patients (nos. 2 and 4) had mean intraocular pressures within normal limits for the last 18-24 months of the study, a finding not unexpected from the results of Sorenson et al. ${ }^{3}$ Secondly, patients 1 and 6 developed occasional intraocular pressures $>21 \mathrm{mmHg}$ during the last 18-24 months of the study, again a finding to be expected in any group of uniocular hypertensives. It should be noted, however, that there was a consistent difference of $>5 \mathrm{mmHg}$ in the intraocular pressure between the 2 eyes in patients 1 and 6 .

The results of the individual tests may be discussed separately.

SUBJECTIVE TESTING

Visual field. All patients had normal 3 isopter Goldmann and Friedmann field charts when entered into the study. Patient 7 developed a consistent field defect within the first 12 months. The remaining patients had greater variability in response to visual field testing in the hypertensive eye (a feature noted by Werner and Drance ${ }^{19}$ as occurring prior to persistent field defects). This variability could be detected on photopic static Tubingen field and Friedmann field testing and to a less extent in scotopic static field testing, but not on assessing the peripheral field. It should be noted, however, that the variable responses were not consistently found in any one quadrant for a particular eye and that, while on one occasion a particular quadrant showed reduced or variable sensitivity, repeated testing gave normal responses for that quadrant but reduced sensitivity from another quadrant.

These variable responses were occasionally seen in the normotensive eye. It could not always be said, on the basis of a single visual field test, which eye was hypertensive for the patients in this study. Repeated visual field testing, however, clearly showed a greater incidence of variable responses in the hypertensive eye.

These results compare with the reproducible responses obtained on static testing of normal patients. ${ }^{19} 25$

A careful check of the pre- and postmydriasis intraocular pressures at the time of visual field 
testing could not relate reduced sensitivity to exceptionally high intraocular pressures for any patient (for it is known that elevating intraocular pressure produces, or increases the size of, visual field defects. ${ }^{19}$ ). In similar fashion the variable responses found by Donovan et al. ${ }^{23}$ were not related to variations in intraocular pressure. While it is possible for the higher incidence of variable responses in the hypertensive eye to have been brought on by the higher postmydriasis pressures found on some occasions (Table 1), the highest recorded intraocular pressures were not always associated with the lowest retinal sensitivity.

Hundred hue. Hundred hue testing was not helpful in distinguishing between the 2 eyes for the patients in this series. This is in contrast to the results obtained by Lakowski ${ }^{20}$ for groups of ocular hypertensives and normals. Despite the small size of the series here, direct comparison of 2 eyes should have indicated a consistently higher score in the hypertensive eye if this test was to have been of clinical use.

\section{OBJECTIVE TESTING}

Serial optic disc analysis. The fact that no change could be detected on analysis of the serial disc photographs may reflect only the short duration of the study. Patient 7, who was found to have a persistent visual field defect in the first 12 months of the study, had a localised notch in the neuroretinal rim and no visible nerve fibres throughout the study. No patient was seen to develop slit-like defects in the nerve fibre layer. ${ }^{18}$

Comparison of paired stereo photographs from each patient. With the exception of patient 4 , who was considered to have optic disc cups of equal size, the writers correctly identified the hypertensive eye as having the larger optic cup. The larger cup showed predominantly vertical elongation rather than overall enlargement (Fig. 3). There was no difference in the visibility of the nerve fibre layer between the 2 eyes except in patient 7 .

Quantitative measurement of cup/disc ratios. The 2 eyes of a normotensive patient have optic cups that are very similar in size both in the size of the optic cup orifice ${ }^{16}$ and in the volume of the optic disc cup. ${ }^{17}$ This similarity in size reflects the similarity in size of the optic discs of any one patient. However, unequally sized optic discs have unequally sized optic cups. ${ }^{26}$ Therefore in patients with slight dissimilarity in the size of the 2 optic discs a straight comparison of the optic cup sizes seen in the 2 eyes of any one patient might give a misleading impression of asymmetry and, from this, suggest an acquired change from elevated intraocular pressure. This appearance was seen in patient 2 (Fig. 4), who was considered to have dissimilar cup/disc ratios in the 2 eyes on subjective analysis but who in fact had very similar cup to disc ratio in the 2 eyes. Because of these possible errors in subjective analysis, quantitative measurement of the C/D ratio and then comparison of the measurements obtained for the 2 eyes of each patient should be more accurate. The patients in this series were found to have a larger C/D ratio in the hypertensive eye (except in the 2 patients whose intraocular pressure reverted to normal during the study), making it likely that the difference between the $C / D$ ratio in the eyes was an acquired change.

\section{Conclusions}

Hypertensive eyes in this study have been shown on visual field analysis to have variable responses on static field testing. These responses are similar to those noted by Werner and Drance ${ }^{19}$ to progress to permanent visual field defects, although there is no evidence that this change will occur for the eyes in this series. The greater variability in responses of the hypertensive eye was apparent only on serial visual field testing rather than on examination of the responses obtained at the time of a single visual field test. Subjective and quantitative assessment of C/D ratios demonstrated larger ratios in the hypertensive eye, but did not show changes in the nerve fibre layer to equate with the visual field response. Serial disc photography may need to be continued for more than 3 years before sequential changes become visible at the optic disc. Stereo disc photography was able to detect (presumed) change at the optic disc before permanent reduction in visual field could be detected. Stereo disc photography, as described, is a quick and simple method of documentation and should be considered for long term follow up of the ocular hypertensive patient.

We thank Professor John Gloster for helpful comments, the surgeons at Moorfields Eye Hospital, City Road, London, for permission to study their patients, Miss K. MacLeod who typed the manuscript, and $\mathrm{Mr} \mathrm{C}$. Clements for photographic assistance.

\section{References}

${ }^{1}$ Hollows FC, Graham PA. Intraocular pressure, glaucoma and glaucoma suspects in a defined population. $B r J$ Ophthalmol 1966; 50: 570-86.

2Perkins ES. The Bedford glaucoma survey. I. Long term follow up of borderline cases. $\mathrm{Br} J$ Ophthalmol 1973; 57: 179-83.

${ }^{3}$ Sorenson PN, Nelson NV, Norskov K. Ocular hypertension, a 15 year follow up. Acta Ophthalmol (Kbh) 1978; 56: 363-72.

'Becker B, Christiansen RE. Water drinking and tonography in the diagnosis of glaucoma. Am J Ophthalmol 1956; 57 : 563-9. 
${ }^{5}$ Sugar HS. Pigmentary glaucoma: a 25 year review. Am J Ophthalmol 1966; 62: 499-507.

${ }^{6}$ Becker B. Diabetes mellitus and primary open angle glaucoma. Am J Ophthalmol 1971; 71: 1-13.

'Paterson G. Nine year follow up of studies on 1st degree relatives of patients with glaucoma simplex. Trans Ophthalmol Soc UK 1970; 90: 575-8.

${ }^{8}$ David R, Livingston D, Kuntz MH. Ocular hypertension, a comparative follow up of black and white patients. $\mathrm{Br} J$ Ophthalmol 1978; 62: 676-8.

${ }^{9}$ Kitazawa Y, Horie T, Aokie S, Suzuki M, Nishioka K. Untreated ocular hypertension. A long term prospective study. Arch Ophthalmol 1977; 95: 1180-4.

${ }^{10}$ Schappert-Kimmijser S. A five year follow up of subjects with intraocular pressures of 22-30 without anomalies of visual field or optic nerve typical for glaucoma at first investigation. Ophthalmologica 1971; 162: 289-95.

${ }^{11}$ Becker B, Horton WR. Topical epinephrine in glaucoma subjects. Am J Ophthalmol 1966; 62: 272-5.

${ }^{12}$ Wilensky J, Podos SM. Prognostic parameters in primary open angle glaucoma. In Symposium on Glaucoma. St Louis: Mosby, 1975.

${ }^{13}$ Schwartz JT, Reuling FH, Feinlab M, Garrison RJ, Colle DJ. Twin study on ocular pressure following topically applied dexamethazone. Arch Ophthalmol 1973; 90: 281-6. ${ }^{14}$ Rosenthal AR, Payne R. HLA typing in chronic simple glaucoma. Presented at Spring ARVO meeting. Sarasota, Florida. 1978.

${ }^{15}$ Drance SM, Saheb NE, Schulzer M. Response to topical epinephrine in chronic open angle glaucoma. Arch Ophthalmol 1978; 96: 1001-2.

${ }^{16}$ Fishman RS. Optic disc asymmetry. A sign of ocular hypertension. Arch Ophthalmol 1970; 84: 590-4.

${ }^{17}$ Portnoy GL. Photogrammetric analysis of volume asymmetry of the optic nerve head cup in normal, hypertensive and glaucomatous eyes. Am J Ophthalmol 1975; 80: 56-9.

${ }^{18}$ Sommer A, Miller NR, Pollack I, Maumenee AE, George $T$. The nerve fibre layer in the diagnosis of glaucoma. Arch Ophthalmol 1977; 95: 2149-56.

${ }^{19}$ Werner EB, Drance S. Early visual field disturbances in glaucoma. Arch Ophthalmol 1979; 95: 1173-5.

${ }^{20}$ Lakowski R, Bryett J, Drance SM. Colour vision in ocular hypertension. Can J Ophthalmol 1972; 7: 86-9.

${ }^{2}$ Spaeth GL. Fluorescein Angiography-Its Contribution Towards Understanding the Mechanism of Visual Loss in Glaucoma. Trans Am Ophthalmol Soc 1975; 63: 491.

${ }^{22}$ Hitchings RA, Spaeth GL. The optic disc in glaucoma 1: Classification. $\mathrm{Br} J$ Ophthalmol 1976; 60: 778-85.

${ }^{23}$ Donovan $\mathrm{H}$, Weale RA, Wheeler C. The perimeter as a monitor of glaucomatous change. Br J Ophthalmol 1978; 62: 705-8.

${ }^{24}$ Gloster J. Vertical ovalness of glaucomatous cupping. Br J Ophthalmol 1975; 59: 721-4.

${ }^{25}$ Greve EL, Verduin WM. Detection of early glaucomatous damage, Part I. Visual field examination. In 2nd International Visual Field Symposium. The Hague: Junk, 1977.

${ }^{26}$ Anderson DR. Clinical evaluation of the glaucomatous fundus. Symposium on Glaucoma. St Louis: Mosby, 1975. 